\title{
Fabián Casas, La supremacía Tolstoi y otros ensayos al tuntún.
}

Buenos Aires: Emecé, 2013, 232 pp. ISBN 9789500435710.

\section{Pablo Brescia}

University of South Florida. Tampa, Estados Unidos pbrescia@usf.edu

Como en el caso de Ensayos bonsái (2007), su primer libro en el género, en apariencia no hay integración en los textos que componen La supremacía Tolstoi y otros ensayos al tuntún salvo las tapas del libro que los contiene. A pesar de esa voluntad manifiesta -la expresión "al tuntún" quiere subrayar lo misceláneo del contenido- cuando se lee hay un impulso hacia la unidad, incluso en la diversidad. En este caso y en estos ensayos, ciertas marcas hablan de un "estilo" Casas.

Por un lado, la voz. Es una voz que busca la naturalidad de un yo informal, sin rigideces, que se permite tocar en apariencia una multitud de temas (diríamos, antaño, que mezcla la cultura "baja" con la "alta"), que le dice al lector: eres como yo, o casi. Por eso, "Un día en la cancha" comienza con una referencia al grupo de rock Queen. Un ensayo sobre uno de los próceres musicales argentinos, Luis Alberto Spinetta, inicia: "Tomá, Luis, mañana es navidad" (29). Y el artículo sobre la perra de Casas, "Lovely Rita", empieza así: "Todos los problemas surgen cuando uno tiene que abandonar su habitación, escribió Pascal" (105).

Por otro lado, los temas. Las piezas de La supremacía Tolstoi y otros ensayos al tuntún, breves y potentes casi todas, testimonian las obsesiones de Casas: el fútbol, el karate, tal vez el boxeo; la música, principalmente el rock; el cine; la familia; la política; la literatura, en sus variadas formas, que en este libro se llaman Naipaul, Coetzee, Borges, Tolstoi, Zambra, Salvador Benesdra, Lem, Bradbury.

Así, se va formando el estilo Casas. En "La supremacía Tolstoi", por ejemplo, uno de los textos más largos del libro, se discuten las ideas de 
Teodoro Adorno sobre la música (extrapolables a la literatura). Casas dice: "Argumentaba que un director de orquesta no podía repetir la obra como había sido ejecutada en el momento de su creación. En cambio, proponía, el director de orquesta debía mediar entre pasado y presente, transformando la obra con su propia obra interna. Es decir que para ser fiel a su material, para extraerle el significado, paradójicamente, el director debe transformar ese material alterando su tiempo, su articulación y su expresión. Adorno, parece, estaba hablando de hacer un cover" (180). En ese giro, en ese desliz entre el desarrollo extenso de una idea -que termina con la palabra "expresión"- y el comienzo de un registro diferente, que sobresalta lo anterior, que lo dinamita para construir otra cosa, en otro plano -el comienzo de la oración "Adorno"- Casas se juega la vida, metafóricamente hablando. Y, metafóricamente, también preguntémonos si no podría verse la frase anterior como una teoría sobre la producción y la recepción del texto literario, algo que siempre está rondando la escritura de Casas.

Así escribe sobre el fútbol: "Parecíamos un dibujito de Escher, cada cuerpo era la continuidad del otro" (13). Esa crónica es de las mejores cosas que le he leído a un escritor sobre ese deporte. Así escribe sobre literatura: "Naipaul es de derecha, como la naturaleza: los débiles deben morir para que surjan los más fuertes y la especie se mantenga sana” (25). Este es un gran ensayo sobre las biografías. Así escribe sobre su fascinación por el karate, mezclando vida y obra: "Yo fui a karate para que mi mente no se me escape, para no estar pensando constantemente en una larga vida y terminar en la ignominia, para parar el diálogo, la máquina de pensar en Gladys y para lograr ser humilde, aprender un nuevo idioma, empobrecerme y habituarme a estar en estado de eterno principiante" (66-67). Así escribe sobre la familia: "En la vida nos tocan seres oscuros y luminosos, aprendemos de los dos" (75). Así escribe sobre música: "Marcus y Reynolds son periodistas que empezaron reseñando discos de rock y a través de lecturas cruzadas se 'desespecializaron': Derrida, Barthes, Deleuze, Kristeva, Benjamin hacen mosh con Johnny Rotten, el postpunk, los Beatles, la cultura rave o Bob Dylan" (152). Dice a propósito de la apropiación de la conocida figura del cómic argentino El Eternauta, insertando al ex presidente Néstor Kirchner en el reconocido traje espacial del personaje: "El kirchnerismo vacía de contenido todo, es una épica de juguete para una época oscura" (172-173). Así escribe sobre política. 
Estos ensayos buscan una empatía con el lector, pero sobre todo en ellos se articula una poética personal basada en cuatro pilares: (1) La búsqueda de la emoción y hasta de la epifanía (véase fútbol); (2) una estética de la mezcla, donde todo se coloca horizontalmente y se privilegian los cruces heterodoxos sin dejar de anotar hipocresías políticas o sociales (véase la música y la política); (3) una apuesta firme por la idea de homologar vida y literatura como actividades donde la ética está en primer lugar (véase Naipaul y el karate) y (4) la noción del maestro y del aprendizaje (karatefamilia-literatura) como fundamento esencial de la vivencia existencial y literaria, resumida en una máxima de cabecera del Sensei Funakoshi, citado por Casas: "Idee en todo momento, idee siempre" (68).

Como detalle saliente, Casas vuelve una y otra vez a la obra de Salvador Benesdra, un "personaje literario" como pocos: hablaba siete idiomas, era nadador y bailarín de salsa, y tuvo graves brotes de psicosis, entre otros, la pesadilla de una invasión extraterrestre que pretendía robarse el Obelisco de Buenos Aires (¿un nuevo Eternauta?). Se mató tirándose de un décimo piso. Casas no se aprovecha de estas circunstancias: sólo habla de sus novelas, El traductor y El camino total como textos valientes, transformadores. Aquí, nuevamente está el enlace entre la poética-ética, el karate, Benesdra: “Como todos los grandes escritores, Salvador Benesdra escribía en contra de su habilidad" (161-162).

En toda miscelánea hay piezas prescindibles: "La venganza de Palito" e "Hijo de Dios" prueban a ser graciosos, pero no sale muy bien que digamos. En el último ensayo del libro, "La solarística”, como si fuera el movimiento final de una sinfonía, Casas hace una combinación que serviría como un digno epígrafe al libro. Va a Chile porque lo han invitado de la Cátedra Bolaño de la UDP en Santiago. Y comienza: "Voy a escribir sobre la amistad, sobre la ciencia ficción, sobre la idea de país, sobre los símbolos patrios, sobre un extraño océano compuesto por la materia de nuestros sueños y terrores. Sobre la nostalgia. Voy a escribir acerca de cosas que no tengo en claro..." (215).

La fuerza del compromiso de Casas (con la vida; con la literatura) es llamativa y nos llama. Por eso, cuando lee a Tolstoi dice que las preguntas que se hacen los personajes de Ana Karenina siguen vigentes: ¿Para qué seguir si la muerte se lo lleva todo? ¿Hay algo trascendente? ¿Controlar o alimentar los apetitos? Y se permite dudar de la literatura y de la vida que, al fin y al cabo, es lo que hace todo escritor que se precie de serlo. 
Como Casas recomienda leer a Tolstoi, modifiquemos un poco esas últimas líneas de su ensayo sobre el escritor ruso y digamos: "Mientras tanto, leamos a [Casas]" (211). 